\title{
Barriers to health care by women infected with Tuberculosis in Kibera slums in Nairobi, Kenya
}

\author{
Hildah Essendi ${ }^{1}$ and Simiyu Wandibba ${ }^{2}$ \\ hildah.essendi@gmail.com
}

\section{Abstract}

Although more men than women die from TB, the disease causes more deaths among women than all causes of maternal mortality combined. Despite TB testing and treatment being free of charge in all government health facilities in Kenya, fewer women than men access this care. This descriptive study explores the TB awareness level among Kibera residents and the barriers faced by women infected with the disease in accessing TB health care. The data used are from 100 household interviews, 5 case studies with female TB patients and 5 key informant interviews with health workers. While an awareness level of $T B$ is above average, there are still some gaps in the knowledge regarding TB treatment, leading to poor compliance with treatment. There is also high stigma associated with TB and HIVIAIDS and poverty. Efforts to improve care seeking among female TB patients in Kibera have to target all these barriers.

Key words: Tuberculosis; women; HIV/AIDS; urban poor; Kenya

\section{Résumé}

Bien que plus d'hommes que de femmes meurent de la tuberculose, la maladie est la cause de plus de décès chez les femmes que toutes les causes de mortalité maternelle combinées. Malgré la gratuité du dépistage et du traitement de la tuberculose dans tous les établissements sanitaires publics au Kenya, moins de femmes que d'hommes ont accès à ces soins. Cette étude descriptive examine le niveau de sensibilisation sur la tuberculose parmi les habitants de Kibera et les obstacles rencontrés par les femmes infectées par la maladie pour avoir accès aux soins de santé. Les données utilisées comprennent 100 interviews auprès des ménages, 5 études de cas avec des femmes atteintes de tuberculose et 5 entretiens avec des travailleurs de la santé. Alors que le niveau de sensibilisation sur la tuberculose est supérieure à la moyenne, il ya encore quelques lacunes dans les connaissances concernant le traitement de la tuberculose, menant ainsi à une faible observance du traitement. II ya aussi une forte stigmatisation liée à la tuberculose, le VIH / SIDA et la pauvreté. Les efforts pour améliorer le recours aux soins chez les femmes atteintes de tuberculose à Kibera doivent cibler tous ces obstacles.

I. Hildah Essendi is a research student in Demography at the Faculty of Social and Human Sciences at the University of Southampton, and a Senior Research Assistant at the Centre for Global Health, Population, Poverty and Policy (GHP3) at the University of Southampton. Highfield Campus, SOI7 IBJ, United Kingdom.

7. Simiyu Wandibba is a Professor of Anthropology at the Institute of Anthropology, Gender and African Studies, University of Nairobi. P.O. Box 30197, 00100 Nairobi, Kenya. 
Mots clés: Tuberculose, femmes, VIH/SIDA, pauvres en milieu urbain, Kenya

\section{Introduction}

It is estimated that 9. 77 million new cases of tuberculosis (TB) occurred in ¿007 compared with 9. $\square 4$ million new cases in $\square 006$, of which a majority were in Asia and Africa'. Although the cases of TB had been on the decline for about 40 years, TB incidence rates started rising and this continues to happen at an alarming rate especially in sub-Saharan African countries with high HIV prevalence, making it the leading cause of death among people infected with HIV ${ }^{\square}$. HIV infection and the AIDS pandemic complicate the TB epidemiology and control because TB is the most significant and life-threatening opportunistic infection for HIV. It is therefore the leading cause of death among HIV positive people because with the compromised immune system resulting from HIV infection, TB can easily thrive and eventually cause death ${ }^{\square}$. Indeed, the World Health Organization reports that up to $80 \%$ of people infected with TB in countries with high HIV prevalence also test positive for $\mathrm{HIV}^{3}$. The organization estimates that there were about I.37 million new cases of TB globally among people infected with HIV and, alarmingly, about 456000 of these people died despite the fact that TB is curable ${ }^{\square}$. Reports also indicate that of the I.3 million people who died of tuberculosis in $\square 008,3.6$ million women fell ill with TB, of whom 700000 died from TB, including $\square 00000$ who were co-infected with HIV $\square, 4-6$.

Although TB kills more young people and adults than any other infectious diseases, it is the world's biggest killer of women ${ }^{5}$. According to the World Health Organization, although more men die from TB than women, women bear a disproportionate burden of poverty, ill-health, malnutrition and disease $^{6,7}$. TB causes more deaths among women than all causes of maternal mortality combined ${ }^{8}$. The World Health Organization estimates that I million women would have died in $\square 005$ and 0.5 million, mainly between the ages of 15 and 44, would have become sick from the disease ${ }^{6}$. In Kenya, although TB treatment in all government health facilities is given free, the estimated case identification is still low, at $50 \%$ and while the number of new cases in the country appears to be declining, the number of patients requiring re-treatment has increased 4,9 .

\section{Literature review and theoretical framework}

The World Health Organization identifies TB as one of the most important emerging global health threats, with an estimated one-third of the world population infected with the causative agent. Nevertheless, TB is not specific to national borders; its impact is being felt in every community across the globe, from the poorer developing states to the wealthy industrial economies ${ }^{7}$. The disease has a serious socioeconomic impact on both the developed and developing world ${ }^{7}$. The developing world has however felt the impact of TB and other communicable diseases more than the developed world ${ }^{7}$. In sub-Saharan Africa, the rise in TB cases 
has been faster, especially due to the high HIV prevalence. It is estimated that while the prevalence of latent TB in sub-Saharan Africa is $31 \%$, that of HIV is $5 \%-35 \%$ of the adult population and one-third to one-half of individuals infected with HIV are co-infected with Mycobacterium Tuberculosis 10,11. Without proper treatment, approximately $90 \%$ of those living with HIV die within months of contracting $\mathrm{TB}^{\mathrm{I}} \mathrm{T}$. The majority of the people co-infected with both diseases live in sub-Saharan Africa where poverty is a major contributing factor to the spread of infectious diseases, TB included. Studies into infectious diseases show that they are prevalent in places where the people are poor 13,14 .

Kenya is facing a failing health care system which is reflected in increased Tuberculosis cases and failure to ensure access of health services to all its populace $^{15}$. The country has a large and rising tuberculosis disease burden and is ranked IOth among the world's $\square$ countries with a high tuberculosis burden ${ }^{4}$. A survey conducted in the country indicates that the Kenyan situation is more alarming with more than $50 \%$ of the public hospital beds occupied by patients with TB related complications $^{16}$.

The urban poor are more affected regarding health issues, with a majority of people living in slum settlements having worse health outcomes compared to those living in non-slum areas or rural areas ${ }^{17-[0}$. This is because the conditions in the slum areas facilitate an increased burden of disease as they are characterised by deprivation, risky health behaviours, and environmental pollution. Additionally, residents of urban slums are most often systematically excluded from government health planning, opportunities, capacity, and empowerment that would otherwise improve their health ${ }^{\square I}$. Consequently, most of the TB cases diagnosed in Kenya are among the poor, who have worse health indicators than the nonpoor $17, \square, \square 3$. Furthermore, the disease poses a threat to women's health security.

The World Health Organization estimates that although more men die from TB than women, women bear a disproportionate burden of poverty, illhealth, malnutrition and disease, conditions contributing to increased deaths among women than all causes of maternal mortality combined, with more than 900 million women being infected with TB worldwide $\square$. Further, it is estimated that by $\square 005$, I million women would have died while 0.5 million, mainly between the ages of 15 and 44, would have become sick from the disease ${ }^{\square 4}$. There exist other impacts of TB infection on women, making the study of the barriers of TB infection among urban poor women urgent. The risk of giving birth prematurely or having a baby with low birth weight doubles for women with TB, and those who receive a late diagnosis are four times as likely to die in childbirth $\square 5$.

Despite the overwhelming impact of TB on the health of women, studies on the impact of gender on health has been largely ignored, particularly in TB research and control efforts ${ }^{26}$. Although various reasons have been advanced for the high TB incidence among women, including delay to seek health care ${ }^{8}$, very few studies have explored in detail the reasons contrib- 
uting to this delay. An effort to improve the health of urban poor women is therefore urgent. This study seeks to explore the awareness level regarding symptoms and treatment of TB among Kibera residents and the barriers women infected with the disease in the slum face in accessing TB health care. The study therefore aimed to answer this basic question: What is the awareness level and the barriers to health care by women infected with tuberculosis in Kibera slums?

\section{Health Belief Model (HBM)}

This study employs the Health Belief Model (HBM) to explain the actions or inactions taken by the women infected with TB in Kibera when seeking care. $\mathrm{HBM}$ is a psychological model that attempts to explain and predict health behaviours by focusing on the attitudes and beliefs of individuals $\square^{7}$. The key variables or assumptions of the model are based on the understanding that a person will take a health-related action based on perceived threat of the condition (in this case TB testing and treatment by women in Kibera). Perceived threat comprises two parts including perceived susceptibility and perceived severity of a health condition. A patient's subjective perception of the risk condition determines what action they take because they perceive the susceptibility associated with the condition. In addition, feelings concerning the seriousness of contracting a health condition or of leaving it untreated-thereby constituting the perceived severity of the condition-determines the action taken by women infected with TB in Kibera slums.

The perceived benefits - the believed effectiveness of strategies designed to reduce the threat of illness and perceived barriers, that is, the potential negative consequences that may result from taking particular health actions, including physical, psychological and financial demands have an implication on the action taken during TB illness. In addition, the various Cues to Action, including the events and either the bodily (physical symptoms of a health condition) or environmental (media publicity) issues motivate people to take action during illness. Other variables determining the action taken during illnesses include the diverse demographic, socio-psychological, and structural variables that affect an individual's perceptions and thus indirectly influence health-related behaviour. An individual's Self-Efficacy or the belief in being able to successfully execute the behaviour required to produce the desired outcomes also has a bearing on the action taken by women infected with TB.

\section{Methods}

Study area and population

This is a descriptive study conducted in Kibera slums of Nairobi. Kibera is the largest slum in Nairobi with an estimated population of between 600,000 and 1.5 million inhabitants, depending on the season. The slum is located about 5 kilometres ( 3 miles) southwest of the city centre of Nairobi and lies on an area of approximately $\square .5$ square kilometres (0.965 square miles), accounting for less than $1 \%$ of Nairobi's total area while holding more than $\square 5 \%$ of its population ${ }^{\square 8}$. It is composed of nine villages and the living conditions, just like in other slums, are deplorable, and 
most of its residents lack access to basic services, including electricity, safe water, toilets, sewerage and garbage collection ${ }^{\square 8,17}$. Housing is extremely poor, with many residents living in oneroomed houses made of semi-permanent materials such as mud, wooden planks or metal sheets ${ }^{17}$. Additionally, over 50 percent of the population in Kibera lives below the poverty line 17. Residents try to sustain themselves through various means, including informal sector activities such as petty trade or casual labour ${ }^{17}$.

Table I Categories of data collected in this study

\begin{tabular}{llc}
\hline Category & Level of data collection & Number \\
\hline Questionnaires & Household & 100 \\
Case studies & Community & 5 \\
\hline Key informant interviews & Health facility & 5 \\
\hline
\end{tabular}

\section{Data collection}

This study uses both qualitative and quantitative data collected in Kibera slums between May and June $\square 006$ to describe the situation of health-seeking by Kibera residents when infected with TB (See Table I). Quantitative data was collected at households using semistructured questionnaires while qualitative data was collected from health care workers in health facilities in the slum using key informant interviews and case studies were administered to women infected with TB in the slum. The study used both probability and non-probability sampling methods. A sampling frame consisting of all households in the slum area was obtained from the Central Bureau of Statistics. Five villages out of nine were then sampled by the use of simple random sampling. Out of these five villages, 100 households were randomly selected without replacement to participate in the study. Visits were made to the selected households where a questionnaire was administered to the head of the household. Interviews at the household sought to get the community's knowledge of TB, its causes and symptoms and the modes of transmission. Other data collected at the household included the barriers that women experience whenever they need to seek for health care when they are infected with TB. Women suffering from TB or those who have ever suffered from TB were selected using the purposive method of sampling. In this method, the informants are selected to meet the study's needs through the health facility where, 5 female TB patients were selected purposively and then case studies conducted on them. These women who had ever suffered from $T B$, or who are suffering from TB were interviewed in order to understand the barriers that they encountered when seeking health care. By administering case studies, the researcher was interested in in-depth narrative accounts of their TB status including the choices they made regarding health care seeking when they contracted TB. The key informant interviews on the other hand were administered to five strategically 
selected, knowledgeable individuals, representing different perspectives on the situation of TB in the community. These opinion leaders were health personnel working in various health facili- ties in Kibera who were selected randomly and interviewed in order to understand the barriers to TB healthcare by Kibera residents.

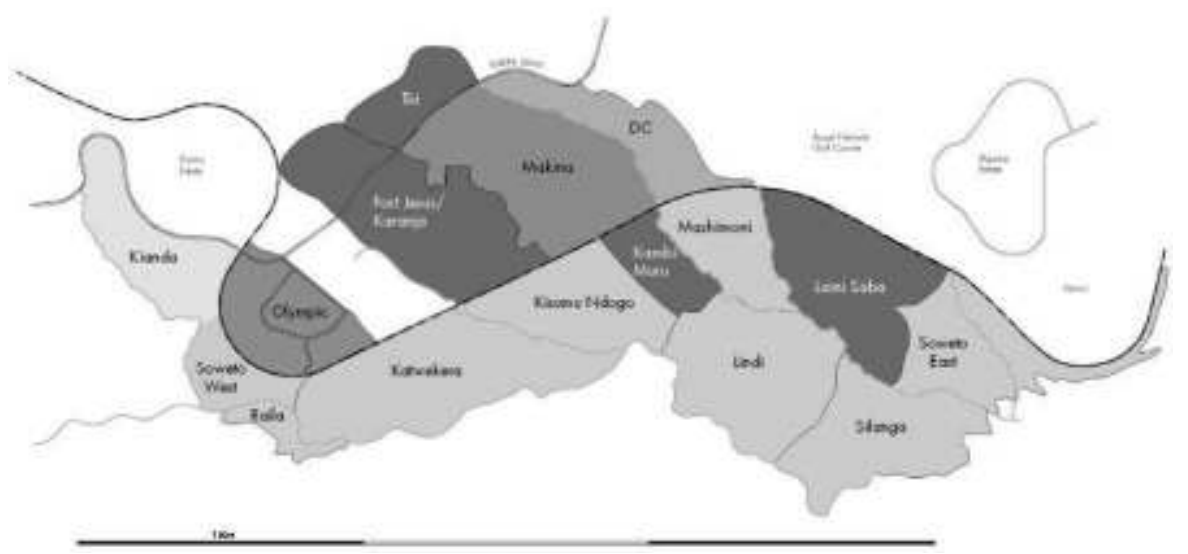

Figure I Map of Kibera Slum

Source: Carolina for Kibera

Using the Statistical Package for Social Sciences (SPSS), data from the questionnaires was analysed by running percentages and frequencies to show the distribution. The data was categorised, arranged, summarised and presented using summaries, tabulations, pie-charts and comparative bar graphs. Data from the key informant interviews and case studies were analysed using content analysis and was presented in form of quotes. The quotes extracted from the qualitative data were incorporated in the paper and are used to compliment the results of the quantitative data. The quantitative and qualitative results are presented side by side in this paper.

\section{Results}

1. Socio-economic characteristics of the respondents

A majority of the respondents to the household questionnaire (7I\%) were women with more than a half of them (58\%) being married while $30 \%$ were single, separated and widowed. More than a half $(6 \square \%)$ of all men interviewed were married while $37 \%$ of all respondents had completed secondarylevel of education with $45 \%$ and $6 \%$ having acquired primary-level and tertiary education respectively. In addition, $69 \%$ of the respondents were Christians while $\square 6 \%$ were Muslims. A majority $(45 \%)$ of the respondents did not engage in any income generating activities, $[0 \%$ engaged in own business, while another $\square 0 \%$ were teachers and one was a landlord. Forty five percent of the respondents had completed primary level of education, while $37 \%$ had completed secondary level of education. Only six $(6 \%)$ respondents had attained college or university education.

The age ranges of women respond- 
ing to the case studies were between $\square 5$ and 40 years. All these women had children ranging between $I$ and 18 years and $99 \%$ of these children were living with them at the time of study. Only I woman out of the five had attained secondary education while the rest had not completed primary school.

\section{Awareness of TB}

Attempts were made in this study to investigate what Kibera residents understood by the term tuberculosis. According to the analysis, most of the respondents gave varied responses implying that they understand the cause, symptoms and course of TB both when treated and untreated.

\section{I Understanding the symptoms of TB and how it is spread}

A majority of the respondents had a clear understanding of TB, with $93 \%$ correctly mentioning that TB is treatable, while only $\square$ percent mentioned it as a viral and HIV disease and only $1 \%$ mentioned that it is a disease that results from HIV infection. At the same time, most of the respondents (95\%) understand that TB is a highly contagious disease and that it can be passed on from one person to another, with $71 \%$ of these reporting that it can be passed through air; $45 \%$ reporting that it would be through sharing things like utensils and clothes; 10 through contact with spittle; $3 \%$ through inheritance; $3 \%$ reported that it would happen through sex and $\square \%$ through smoking (See Figures $\square$ \& 3). The clear understanding of TB was reinforced with the qualitative data. Response in a case study with a $\square 5$ year old female TB patient correctly cited TB as “... a coughing disease that people can pass on to others if they cough in the air because the germs stay in the air and are carried by the wind to those who are not infected, so they become sick".

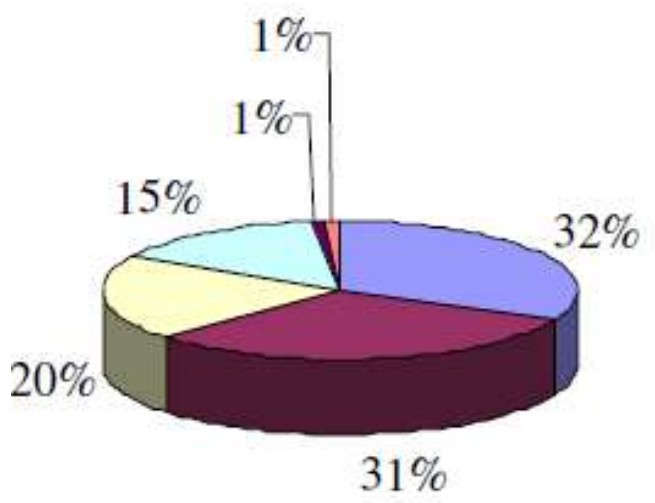

$\square$ Airborne disease

$\square$ Chest disease

A coughing diseas

Lung disease

- Viral disease

An HIV disease

Figure 2 Respondents' understanding of TB 


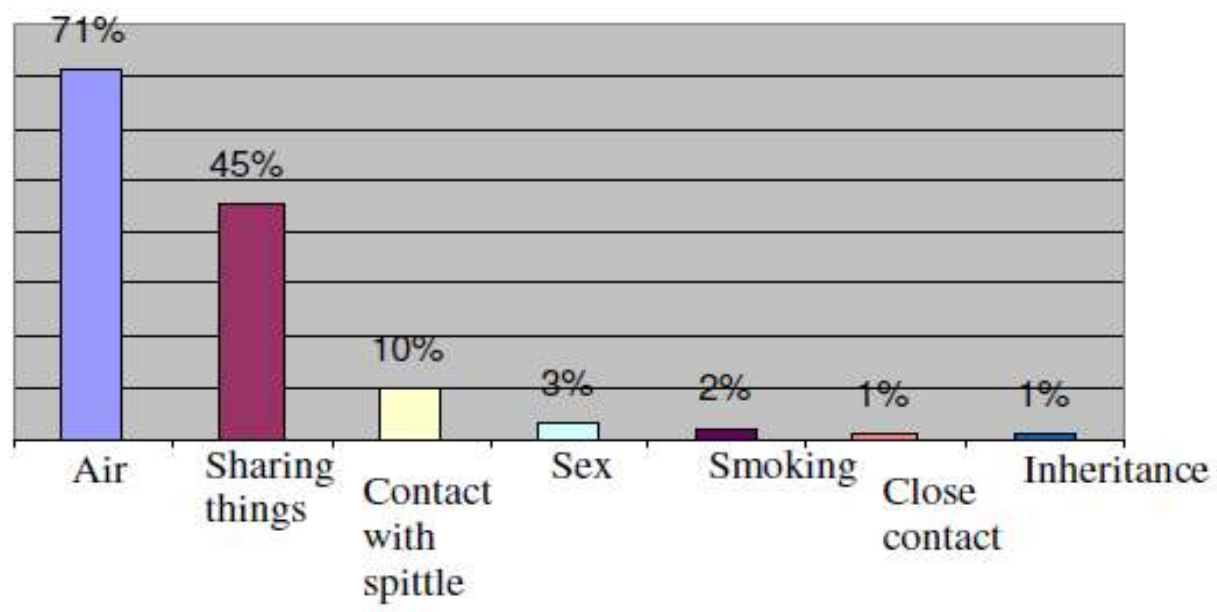

Figure 3 Ways in which TB can be spread

\subsection{Treatment of the disease}

Almost all the respondents (93\%) correctly mentioned that $\mathrm{TB}$ is treatable, while the various symptoms of TB were mentioned; $76 \%$ correctly cited coughing; weight loss (34\%); fever (4「\%); coughing up blood (15\%); night sweats (I4\%) and loss of appetite (10\%). Data from the qualitative studies reinforces the knowledge that residents of Kibera have regarding TB. A 40 year old TB patient interviewed in a case study had this to say about the symptoms of TB following her own experience with the disease: "There is a continued cough...I coughed for one a half years and I also experienced a blocked chest and pain when breathing as well as weight loss and weakness of the body".

Asked about the period of TB treatment, $44 \%$ of the respondents correctly mentioned between 6 and 8 months, while $30 \%$ did not know the period of time taken to treat TB. Six- teen Percent of the respondents mentioned between $\mathrm{I}$ and 5 months and $\square \%$ mentioned between $\mathrm{I}$ and 3 weeks.

\section{Barriers to TB health care}

To assess the barriers faced in accessing services that provide TB diagnosis and treatment, it was necessary to consider all the steps that have to be taken by women infected with the disease in Kibera slums when seeking health care related to the disease. In the qualitative data collected, the female TB patients interviewed were asked to narrate their experiences from when symptoms developed to diagnosis, treatment and cure. These steps make up a pathway that is often represented, for simplicity, as a straight line (Figure 4). This line depicts the steps taken when one develops symptoms of ill health, to then seek help from the relevant health care service, where the ailment will be diagnosed and treatment sought thereafter. 
Adherence to the prescribed treatment therefore eventually leads to a positive outcome where one gets better. In reality however, these steps are rarely followed in a linear sequence; people look for a range of remedies from a variety of providers at all stages of their illness ${ }^{\square 9}$. Sometimes, patients simply do not seek remedy for their illness. In addition, the level of knowledge regarding cause, symptoms and course of treatment determines the treatment taken when one suspects themselves of having TB.

Figure 4 Pathway to accessing TB services

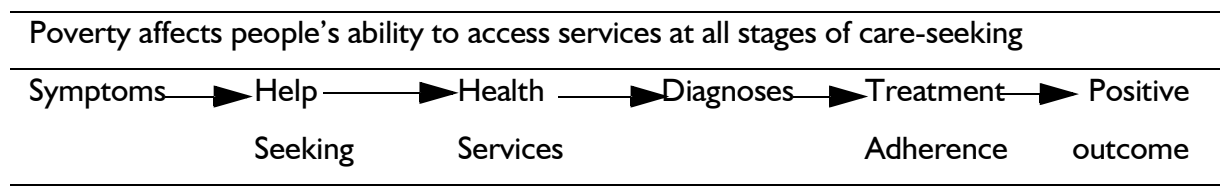

Source: WHO (2005a) ${ }^{29}$

We found that five women from the households visited had recently suffered from TB and delayed to seek treatment for more that two months. From the case studies conducted, all the five respondents had taken more than $\square$ months before accessing care. The reasons that were advanced for this delay were ignorance of the symptoms and lack of time to seek care. The other reasons given for delay in seeking care include stigma associated with HIV, poverty and poor compliance with the treatment, thereby requiring them to undergo treatment several times, once the conditions worsens.

\section{I Ignorance of the symptoms}

Data collected at the household indicates that of the $9 \%$ of the households reporting that there had been a woman in the household suffering from TB, more that $50 \%$ of these women had stayed for more that two months before seeking care and $90 \%$ of them indicated that they delayed to seek care because they were not aware that they were suffering from TB, although they indicated that they had all the symptoms of TB. Qualitative data collected from health workers regarding the reasons why women delay to seek care confirm that residents in Kibera delay to seek care due to ignorance of the symptoms. A health worker indicated that most residents of Kibera delay to seek TB testing and treatment because in the early stages they are not able to distinguish this from symptoms of cold or flu. This quote confirms this: In this facility we receive so many patients suffering from $T B$ and who have stayed for so long before coming to the facility for treatment ... Some patients who visit this hospital even die while undergoing treatment because they come when the disease is too advanced...Our investigations indicate that people from this slum are not able to differentiate the symptoms of tuberculosis from those of the common cold or flu. It is only when they have ailed for such a long period and on the verge of dying that their relatives bring them to the facility.

This fact is also confirmed by data from the case studies, which indicate that failure to differentiate the symptoms of TB and flu caused the delay in seeking care. One TB patient narrated: 
"Many people in this area, and women included, do not understand what the symptoms for TB are. Yes, there is a cough included but many of us just assume it is a cold until it lasts for very long and we become really sick, then people advise us to go to hospital". Further, another health worker from a facility in the slum also cited ignorance of the symptoms as a major hindrance to TB care, thus: "Many of these people never know that it is $T B$ they are suffering from. This is why they take so long to come to hospital, some take as long as two years from the onset of the symptoms". Indeed, the level of ignorance regarding TB treatment was highlighted in the household data where less than a half of the respondents (44\%) correctly mentioned 6-8 months as the period of TB treatment, while $30 \%$ did not know the period of treatment.

\subsection{Stigma associated with HIV and fear to test HIV positive}

The fear of knowing one's HIV status kept women suffering from TB from seeking health care. Although this was not reported in the household interviews, all the participants in the case studies cited this as a major contributing factor to the fear of one going to the hospital for a TB test. This, they said, is because most Kibera residents understand TB to be an opportunistic infection resulting from one's immune system becoming immnosuppressed due to the HIV virus. All the five women responding to the case studies and who had TB were also HIV positive at the time of interview. They further reported that there is stigma related to having TB because whenever one coughs for a long time, there is the fear that they could also be having the virus, and this is enough to keep one from visiting a health care facility for fear of being diagnosed with the virus.

\subsection{Poor compliance with treatment}

Poor compliance as a result of the long period taken to treat TB coupled with lack of awareness of the importance of finishing a treatment course to avoid resistance was cited as a major problem during the treatment of the disease as it delayed full treatment of the disease. A health worker responding to a key informant interview indicated that most patients who come to their facilities for TB treatment rarely observe the dosage of the medication to the end. The result of this is multi-drug resistant TB which, according to the World Health Organization, is more expensive to treat and also takes longer. In addition, it increases the incidences of the resistant strains and has the potential of transmitting this strain. One TB patient cited the long period required to take the drugs as one major contributing factor to non-compliance. The problem with the treatment is that one takes it for such a long period of time and this makes one get bored and stop. When I was tested and found to be having the disease, I got the medicine required to treat the disease. I swallowed the tablets for about two months but then they became a bother and I stopped taking them. Actually I was feeling fine already, so I thought that I was healed.

According to the data from both the respondents and the health care providers, many women are unable to fully comply with the treatment to completion. Out of the five case studies done, one had had recurrent TB due to no-compliance with the treatment given to her, while three others had also 
not been able to complete their dosage of the treatment. Only one more was still in the initial stages of the treatment. According to a health care provider at the IMC, as a result of patients absconding treatment, the health care providers are forced to make followups of all the TB patients that they treat. Being a nongovernmental facility but working with the Ministry of Health in Kibera, the treatment of TB was given free at the time of study. For all those who failed to comply with the treatment instructions by the health care providers, additional treatment had to be given to them. This, according to the IMC health care provider, ensured that resistant TB is treated. The mode of treatment also changes from administration of tablets, to giving of injections.

\subsection{Poverty}

Although TB testing and treatment is given free in government health facilities and non-governmental facilities, qualitative data from the study indicated that delay or failure to seek care was occasioned by their inability to pay for treatment. This was coupled with ignorance about treatment. In addition, with lack of or scarcity of food by residents in the study area, especially those suffering from the disease, compliance to the treatment becomes a tricky issue because taking the drugs on an empty stomach made one weak and therefore stop taking the medication. Without proper diet, a sick person is not able to take her medication effectively. The side effects of the TB drugs also often make the patient weak and may be tempted to stop taking the medication. Some widows who had lost their husbands were disinherited by their hus- band's family and sometimes property taken from them. This was reported to often leave them too impoverished to think and access treatment when they contract TB. In addition, without the necessary support system from family and friends, women suffering from TB can only depend on themselves or their young children for advice and access of treatment as well as provision of basic needs. This quote from a woman with TB confirms: My husband died last year and his family rejected and refused to recognise me as his wife. My husband's family comes from Western Kenya but I come from Uganda. They rejected me and my children claiming that since I was the second wife, I was the one who killed their son. They refused to take care of me yet even at the time I was sick. They came to the house and took all household property forcing me to struggle and fend for myself and the children. But when my condition worsened, my daughter had to stop going to school to take care of me.

\section{Discussion}

Understanding the determinants of health care seeking and barriers faced in health care seeking is crucial because it provides a basis on which policy makers can formulate health policies. It is even more urgent when the focus is on a marginalised group, like the urban poor, whose views have previously been ignored in formulating policies and programs, and yet their views are important in designing policies to address their health. Prior assumptions regarding the urban populace included the fact that their health is better than their rural counterparts because of ease of access to the necessary facilities and because of better infrastructure. Recent 
studies however found that the urban poor experience worse health conditions than their rural counterparts 17. This study investigated the barriers faced by poor urban women in Nairobi in seeking TB care. Aside from seeking to quantify the barriers, this study also allowed female TB patients and community health workers to say, in their own words the barriers that they face in accessing $T B$ care and the results presented are a mix of the qualitative and quantitative data..

One major focus of this study is the perception of TB by Kibera residents. It has been established that perception of an illness is an important determinant of people's health seeking behaviour and understanding this can make a great contribution on efforts to reduce the disease burden. Focusing on the perception of $T B$ is therefore urgent because TB and AIDS have been determined to be the biggest contributors to the burden of disease among the urban poor $^{30}$ and understanding the urban poor's perception of TB is therefore important if the war against TB is to be won $^{31}$. It is clear from the results that although the general awareness of TB, its symptoms and causes were clear, the inability to distinguish the disease from common cold or flu makes it hard for women suffering from TB in Kibera to determine this and therefore seek TB care on time. The current approach to the control and treatment of TB in Kenya relies on passive case finding and thus entirely depends on whether and when people decide to present themselves to a health centre for help $3 \square$. The treatment-Directly observed treatment short-course (DOTS) is a 6-8 months course of treatment adminis- tered to patients infected by TB and a patient can be treated in the clinics, hospitals and at home. If patients fail or delay to seek health care, their condition is worsened. Since Kenya's National Leprosy and Tuberculosis Control Programme (NLTP) began to implement the WHO-recommended DOTS strategy in 1993, it reported 100 percent DOTS coverage by $[00 \mathrm{I} 33$. However, there exist some challenges due to the large TB disease burden in Kenya, making it difficult for the public health sector to continue delivering quality DOTS services ${ }^{33}$.

The various other barriers faced by women infected with TB in Kiberaa slums include ignorance of the symptoms, poverty, stigma associated with HIV and the fear to test HIV positive when they present with TB symptoms at the health facility and consequently, poor compliance of the treatment. Female TB patients in Kibera slums fail to seek care until the condition persists, a finding that is consistent with those from other studies, for instance, two studies conducted in Ethiopia and Manila found that TB patients in general rarely see a doctor for tuberculosis-like symptoms and they only do this if symptoms become extreme ${ }^{31}, 3 \square$. The study measuring the delay of presentation of symptoms in Ethiopia indicated that patients took a mean of 10 weeks from onset of symptoms to diagnosis ${ }^{3 \square}$. In Manila, Philippines, one fifth of the patients had symptoms for at least three months before they approached a health facility ${ }^{31}$. One contributing factor to this situation is the lack of clear understanding of symptoms of TB. Health beliefs and behaviour impact people's health-seeking and many peo- 
ple do not seek health care unless their condition interferes with social or personal activities of daily living, such as work and household maintenance and this is particularly so when the disease has symptoms that are not very clearly understood, like the case of TB ${ }^{34}$.

Further, lack of a clear understanding of TB symptoms and the course of treatment acts a serious barrier to successful fight against TB treatment. Beliefs concerning the cause of the disease are a crucial determinant of subsequent health seeking behaviour as found in a Kenyan study ${ }^{35}$. Echoing the findings of our study, this and other studies to understand the barrier to TB care in Africa found that lack of a clear understanding of the aetiology of the disease often leads to either self-medication of inappropriate treatment, practices that delay appropriate treatment, thereby worsening the condition ${ }^{36,37}$. In our study, lack of awareness of the fact that TB is caused by an airborne, infectious agent increases domestic transmissions and delay TB patients from seeking treatments and finishing the course of treatment. The women interviewed indicated that once they start getting relief in the course of treatment, they stop taking medication.

Self-treatment is also a very common strategy undertaken by both the urban poor and the rural poor ${ }^{38} 39$. For the urban poor, chronic coughs and other common health complaints are most often self-treated at community drug stores which serve as the first treatment-option for most poor people seeking care. In this study, the first treatment sought when one starts coughing is buying of cough medicine from the community drug stores. Without proper understanding of TB treatment, most women infected with TB in Kibera slums continue to self-treat as the symptoms persist, oblivious of the danger of delay in seeking appropriate medical care for the TB symptoms.

Stigma associated with TB and public health services made many patients shy away from seeking health care for fear of being diagnosed with HIV/AIDS. TB/HIV stigma has been widely reported ${ }^{40-4}$. Just like in these studies, our study found that patients postpone seeking care, or are afraid to seek care in health facilities in their neighbourhood due to fears of finding out their HIV status, and suffering stigmatization and social rejection as a consequence of their HIV and TB status becoming known.

Poverty, specifically the lack of money is the main reason for delaying seeking health care. Costs include transport, accommodation and time lost working. Despite TB testing and drugs being offered free of charge in governmental and some non-governmental facilities in the slums, female TB patients still require money to access transport to the facilities. In addition, time taken to access health care implies that there is time lost in meeting their daily needs and this acts as an indirect economic barrier to accessing care. For those who may access this care, compliance is an issue because meeting basic needs is given priority. A recent study in Nairobi slums found that women seeking care in Nairobi slums may delay to do this because preference is given to meeting other basic needs $43^{\circ}$. 


\section{Conclusion}

There is a complex pathway to care for the poor, and this study has found that despite TB being a curable disease, whose treatment is given free of charge in all government health facilities and in some private facilities in Kibera, there is still high morbidity and mortality arising from failure or delay of women to access treatment when infected with TB. Awareness of the causes and course of the disease and of the available testing and treatment services was low among respondents to this study. Continuous education about the symptoms and the importance of early detection and treatment need to be reinforced in order to ensure timely treatment and therefore reduced morbidity and mortality, both of which can be avoided.

Also following from our analysis, poverty among women in Kibera slum was found to be a barrier in accessing health care during TB sickness. This is because with no money to access medical facilities, female TB patients could not access treatment or fully comply with it even after accessing it. Furthermore, stigma was found to be a hindrance to TB health care by women in Kibera slums. Based on the findings of this study, massive educational campaigns need to be established to inform Kibera residents of facts about TB. It is also important to emphasize the importance of separation of the two diseases because having TB does not guarantee HIV infection as well. Most importantly, is the message that TB is curable and yet lack of treatment can lead to death needs to be made.

Tuberculosis projects should focus on educating women and the whole community at large about the disease, showing the importance of early detection of TB, treatment and compliance. More importantly, there is need to create awareness on where to get TB health care services. This would help reduce the time taken to seek care and knowledge on importance of compliance would help ensure treatment is taken fully in order to limit resistance to treatment and therefore transmission of the resistant strain of TB.

\section{Acknowledgements}

This paper was derived from a Master of Arts thesis by one of the authors, "Essendi HM. [007. Barriers to health care by women infected with Tuberculosis in Kibera Slums, Nairobi. Unpublished MA Dissertation. Institute of Anthropology, Gender and African studies, University of Nairobi, Kenya". Essendi would like to acknowledge the role played by her MA supervisor and co-author of this paper, Professor Simiyu Wandibba. The authors also wish to acknowledge Kibera residents for their participation in this research.

\section{References}

I WHO. Global Tuberculosis Control: Epidemiology, Strategy, Financing Report. Geneva: World Health Organization; $[009$.

WHO. Tuberculosis: infection and transmission. http://www.who.int/ mediacentre/factsheets/fs I 04/en/.

Geneva: World Health Organization; ᄃOIO.

3 WHO. Tuberculosis and HIV. Found at http://www.who.int/hiv/topics/tb/ en/. Accessed on March $7 \square 0 \mathrm{O} 0$.

4 WHO. Tuberculosis (TB). Available 
online at http://www.who.int/tb/ publications/global_report/2007/pdfl ken.pdf. Accessed on March 72010 $\square 007$.

$5 \mathrm{WHO}$. Tuberculosis and gender. Found at http://www.who.int/tb/challenges/ gender/en/. Accessed on March 7 $2007 \square 006$.

6 WHO. Women and TB. Geneva: World Health Organization; $\square 009$.

7 WHO. The World Health Report 2003: Shaping the Future. Geneva: World Health Organization; $\square 003$.

8 TB Alert. TB and Women. http:// www.tbalert.org/worldwide/

TBandwomen.php. Accessed June I, $\square 006$.

9 USAID. Tuberculosis profile: Kenya. http://www.usaid.gov/our_work/ global_health/id/tuberculosis/ countries/africa/kenya.pdf. Accessed June $\square 6, \square 010$.

I0 WHO. Global tuberculosis control surveillance, planning, financing. WHO report 2006. Geneva: World Health Organization; $\square 006$.

I Corbett EL, Watt CJ, Walker N, Maher D, Wiliams BG, Raviglione MC. The growing burden of tuberculosis: global trends and interactions with the HIV epidemic. Archives of Internal Medicine. ए003; 163(9): 1009-10ワ।.

I WHO. Global Tuberculosis Control Report. http://www.who.int/tb/ publications/global report/en/.

Geneva: World Health Organization; $\square 004$.

I3 WHO. Malaria cases (per 100,000) by country. Geneva: World Health Organization; $\square 005$.

I4 Needham DM, Godfrey-Faussett P, Foster SD. Barriers to tuberculosis control in urban Zambia: the economic impact and burden on patients prioir to diagnosis. International Journal of Tuberculosis Lung Disease. 1998; $\square(10): 81$ I-8I 7.

15 International Medical Corps (IMC). Medical TRaining and Emergency Care Worldwide. Available online at http:// :www.imcworldwide.org/ Accessed January $22007 \square 006$.

16 Obonyo B, Owino W. Promoting Access to Healthcare through efficiency improvements: priorities and policy options. Nairobi: Institute for Policy Analysis and Research.; 1997.

17 APHRC. Population and Health Dynamics in Nairobi's Informal Settlements. Nairobi (Kenya): African Population and Health Research Center; [00 $\square$.

I8 Magadi MA, Zulu EM, Brockerhoff $M$. The inequality of maternal health care in urban sub-Saharan Africa in the 1990s. Population Studies. ए003;57(3):347-366.

19 Brockerhoff M, Brennan E. The poverty of cities in developing countries. Population and Development Review. 1998; $\square 4($ I ):75II4.

$\square 0$ Hacker A, Ryan C. Prevalence of infant stunting in an urban Kenyan population: comparison to the 1998 Kenya Health and Demographic Survey and the $\square 000$ CDC growth grids. Nutrition Research.

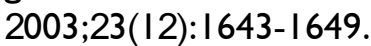

I Mercado S, Havemann K, Sami M. Urban poverty: an urgent public health issue. Journal of Urban Health. ¡007;84(3 Suppl):i7-il 5.

(1) Central Bureau of Statistics Kenya, Ministry of Health Kenya, ORC Macro. Kenya Demographic and Health Survey $\square 003$; $\square 004$. 
$\square 3$ Kiboss JK, Kibitok N. The reemergence of Tuberculosis among the economically productive age group in Kenya: the case of Mombasa district. Journal of Social Development in Africa. $\square 003 ; 18(\square)$.

$\square 4$ WHO. Women's health in South-east Asia. http://www.who.int/whr/2003/ en/.. Geneva: World Health Organization; $[003$.

75 action. Tuberculosis: An Unchecked Killer of Women. http:// www.action.org/site/get_educated/ tuberculosis_an_unchecked_killer_of women: Advocacy to control $\overline{\mathrm{T}} \overline{\mathrm{B}}$ internationally (action); 5010.

$\square 6$ Uplekar M, Rangan S, Ogden J. Gender and Tuberculosis Control: Towards a Strategy for Research and Action. Geneva: World Health Organization; 1999.

$\square 7$ Becker $\mathrm{MH}$. The Health Belief Model and Personal Health Behavior. Health Education Monographs. 1974; $\square(4)$.

$\square 8$ Government of Kenya. National Development Plan, [00Г-[008. In: Development MoPaN, ed. Nairobi: Government Printer; $\square 00$ I.

$\square 9$ WHO. Addressing Poverty in TB Control: Options for National TB Control Programmes. Geneva: World Health Organization $\square 005$.

30 Kyobutungi C, Ziraba AK, Ezeh A, Yé Y. The burden of disease profile of residents of Nairobi's slums: Results from a Demographic Surveillance System. Population Health Metrics. $\square 008$.

3I Auer C, Sarol J Jr, Tanner M, Weiss M. Health seeking and perceived causes of tuberculosis among patients in Manila, Philippines. Tropical Medicine and International
Health. $[000 ; 5(9): 648-656$.

3] Cambanis A, Yassin AM, Ramsay A, Squire SB, Arbide I, Cuevas LE. Rural poverty and delayed presentation to tuberculosis services in Ethiopia. Tropical Medicine and International Health. [005; 10(4):330-335.

33 Chakaya JM, Meme H, Kwamanga $\mathrm{D}$, et al., Planning for PPM-DOTS implementation in urban slums in Kenya: knowledge, attitude and practices of private health care providers in Kibera slum, Nairobi. The International Journal of Tuberculosis and Lung Disease. ए005;9(4):403-408.

34 Tripp-Reimer T, Choi E, Kelley LS, Enslein JC. Cultural Barriers to Care: Inverting the Problem. Diabetes Spectrum. $\square 00 \mathrm{I} ; 14(\mathrm{I})$.

35 Liefooghe R, Baliddawa JB, Kipruto $E M$, Vermeire C, De Munynck AO. From their own perspective. A Kenyan community's perception of tuberculosis. Tropical Medicine and International Health. 1997; [(8):8098ㅁ.

36 Gele AA, Sagbakken M, Abebe F, Bjune GA. Barriers to tuberculosis care: a qualitative study among Somali pastoralists in Ethiopia. BMC Research Notes. [0 10;3(86).

37 Mohamed A, Yousif M, Ottoa P, Bayoumi A. Knowledge of Tuberculosis: A Survey among Tuberculosis Patients in Omdurman, Sudan. Sudanese Journal of Public Health. $\square 007 ; \square(1)$.

38 Hamel MJ, Odhacha A, Roberts JM DM. Malaria control in Bungoma District, Kenya: a survey of home treatment of children with fever, bednet use and attendance at 
antenatal clinics. Bulletin of the World Health. $\square 001 ; 79$ (1014- $\square 3)$.

39 Equi-TB. Barriers to accessing TB care: how can people overcome them? Liverpool: Liverpool School of Tropical Medicine; ND.

40 Gebremariam MK, Bjune GA, Frich JC. Barriers and facilitators of adherence to TB treatment in patients on concomitant TB and HIV treatment: a qualitative study. BMC Public Health. $\square 0$ I0; 10(65I).

4I Sagbakken M., Frich J.C., Bjune G.A. Perception and management of tuberculosis symptoms in Addis Ababa, Ethiopia. Qualitative Healtha Research. [008; I8(10): 1356-1366.

$4 \square$ Daniel OJ, Alausa OK. Treatment outcome of TB/HIV positive and TB/ HIV negative patients on directly observed treatment, short course (DOTS) in Sagamu, Nigeria. Nigerian Medical Journal. $\square 006 ; 15: \square \square \square 6$.

43 Essendi H., Mills S., Fotso J.C. Barriers to Formal Emergency Obstetric Care Services' Utilization. Journal of Urban Health. $\square 010$. 